\title{
Emerging Multimorbidity Patterns and Its Linkages With Selected Health Outcomes Among Working- Agegroup Population: Findings From Odisha, India
}

Sanghamitra Pati ( $\sim$ drsanghamitra12@gmail.com )

ICMR-Regional Medical Research Centre

Parul Puri

International Institute for Population Sciences

Priti Gupta

Centre for Chronic Disease Control

Meely Panda

All India Institute of Medical Sciences

Pranab Mahapatra

Kalinga Institute of Medical Sciences, KIIT University

\section{Research Article}

Keywords: Disease Clusters, Latent Class Analysis, Multimorbidity, Co morbidity pattern, Self-Rated Health, Quality of Life, Primary Care, India.

Posted Date: March 26th, 2021

DOI: https://doi.org/10.21203/rs.3.rs-334448/v1

License: (c) (i) This work is licensed under a Creative Commons Attribution 4.0 International License.

Read Full License 


\section{Abstract}

The study utilized data on 2912 individuals in the age-group 15-64 years collected under the burden of diseases study among patients attending public health care settings of Odisha, India. The findings suggested that $2.4 \%$ of the individuals in the working age-group were affected with multimorbidity. We utilized a latent class analysis (LCA) to identify commonly occurring disease clusters. Based on the LCA model fits, i.e., lowest AIC and BIC values, two latent disease classes were identified. These classes were named low co-morbidity and Hypertension-Diabetes-Arthritis; based on the item responseprobabilities. Binary logistic regression adjusted for age, sex, ethnicity, educationlevel, marital status, socio-economic status, residence, and health insurance, highlighted thatage, belonging to a non-aboriginal ethnicity and urban area increased the risk of being in the'Hypertension-Diabetes-Arthritis'group compared to 'lowcomorbidity' group. Furthermore, $50 \%$ of the individual in the 'Hypertension-Diabetes-Arthritis' group reportedpoor quality of life, whereas $30 \%$ reported poor self-rated health (SRH) compared to only $11 \%$ reporting poor SRH in the 'low-comorbidity' group. Additionally, the mean healthscore reported by the individuals in the 'Hypertension-Diabetes-Arthritis' group was 39.9(scale 0-100) compared to 46.9 by their counterparts.

\section{Introduction}

Multimorbidity is defined as the coexistence of two or more chronic conditions (1). With the rise of chronic non-communicable diseases (NCDs) and increased life expectancy, multimorbidity is becoming a norm rather than the exception. In low- and middle-income countries (LMICs) such as India, the impact of these changes are more explicit due to changes in the lifestyle and environmental exposures which contribute to NCDs (such as an increase in obesity and physical inactivity) along with aging. (1) But the healthcare system is still oriented towards treatment for single conditions and acute diseases. Even the treatment guidelines are based on particular conditions rather than holistic treatment of multiple comorbid conditions. Consequently, patients with multimorbidity need to often visit multiple healthcare providers, which increases the treatment burden, leads to low patient satisfaction and poor health outcomes. (2-4)

A global multi-country study has reported the prevalence of multimorbidity to be high (ranging from 45$71 \%$ ) across LMICs.(5) In another study, covering 28 LMICs, the mean world standardized multimorbidity prevalence for LMICs was $7.8 \%$, among population aged $\geq 18$ years. (6) Prevalence of multimorbidity varied from $4.5-83 \%$ in South Asia. $(7,8)$ Community-based studies from India such as the WHO SAGE survey conducted in 2007-2010 among those aged $\geq 18$ years, reported a prevalence of $20 \%$ (9). Another study conducted among rural elderly reported a prevalence of $60 \%$.(10) In primary care settings the prevalence of multimorbidity increased from $6 \%$ among $18-29$ year olds to $44 \%$ among those aged $\geq 70$ years (11). In all the studies multimorbidity increased with age. Of note, those with multimorbidity were reported to have higher mortality as compared to those with single morbidity.(8) 
Although most studies have focused on older patients, multimorbidity is more prevalent in absolute terms in those aged under 65. However, the impact of multimorbidity in those aged between 15 and 64 is underresearched, and we know little about the clinical and sociodemographic characteristics of the working age population with multimorbidity, their patterns of health and social care use, and the potential changes that could be made to services to manage these patients better.

Recent studies examining comorbidity patterns in noncentenarian populations using correlation analysis $(12,13)$ and latent class analysis(14)revealed that diseases are not independent and tend to compound and interact. Seven comorbidity classes emerged from the data in a study of a large representative sample of Danish adults.(14) While 59\% were classified as having no or just one condition, the other six classes had a very high prevalence of multimorbidity. The most prevalent classes included hypertension (14\%), musculoskeletal disorders (10\%), and mental disorders (7\%).

Thus, there is a need to understand the common patterns of multimorbidity defined as chronic diseases that cluster together most frequently.(15)There were studies which describe disease clusters that occur with the highest frequency or prevalence. However, it may be more meaningful to focus on the associations beyond chance or patterns of diseases, known as associative multimorbidity.(16) Associative multimorbidity is derived by different statistical methodologies, such as observed to expected ratios or odds ratios among the most commonly dyads or triads of chronic conditions, or cluster and factor analyses to identify systematic clusters among diseases. We need a better understanding of the clustering of multimorbidity patterns in the population. Thus, we aimed to explore the profiles of multimorbidity patterns in outpatients of different levels of public health care facilities. Our hypothesis was (a) the presence of distinct patterns with a small but existing proportion of individuals and (b) that these patterns would be associated with sociodemographic (gender, age) and health outcomes (self-rated health).

oth the number of people with multimorbidity

and the prevalence of multimorbidity seem to have

increased in recent years [6],

\section{Methods And Materials}

\section{Data source and sampling design}

The present study utilized data from the survey"burden of diseases among patients attending public health care settings of Odisha-2015", undertaken across ten public health care facilities (REF). The project was conducted under the stewardship of the Department of Health and Family Welfare, Government of Odisha, India. The survey utilized a stratified random sampling design to select the study participants(17). Considering the non-response rate of $10 \%$, a total of 3377 participants were included in the survey in the age-range of 14-95 years(17). However, as the study is based on the working age-group 
population,data on 2912 individuals in the age-group 15-64 years as derived from the original datasetfor the purpose of the present study.

\section{Ethical consideration}

All the survey tools and documentations received an ethical approval from the Public Health Foundation of India (PHFI) research ethics committee(17). They were performed in accordance with the relevant guidelines and regulations.Additionally, all essential prior official permission was acquired to conduct the study at health facilities. An informed consent was obtained from all the study participants after disclosing the purpose and procedure of the study. Confidentiality and anonymity were maintained at all stages of data collection and dissemination(17).

\section{Measures and analysis}

The present study utilized information of 18 self-reported chronic diseases including acid peptic disease, arthritis, chronic back pain, diabetes, epilepsy, filariasis, hearing disorder, heart disease, hypertension, kidney disease, lung diseases, mental disorder, osteoarthritis, skin diseases, stroke, tuberculosis, thyroid diseases and vision disorder to identify frequently occurring diseases groups among the working population (15-64 years) in Odisha, India.

The correlates of the identified latent disease classes were further computed, utilizing variables age-group (15-34 years/ 35-49 years/50-64 years), sex (male/female), ethnicity (aboriginal/non-aboriginal), schooling (no education/ primary/secondary and above), current marital status (in union/not in union), socio economic status (above poverty line/below poverty line), place of living (rural/urban), health insurance (no/yes), and health care facility visited (primary/secondary/tertiary) as predictors and identified latent disease classes as outcome of interest.

Furthermore, the present study utilized three perception-based health outcomes, namely poor self-rated health, poor quality of life and health score. Self-rated Health (SRH) was computed by recoding the responses received from the question, "Would you say that your health is?" The responses for the question had five categories, excellent, very good, good, fair and poor, which were recoded into binary variable poor SRH/not poor SRH.Furthermore, quality of life was assessed utilizing 81 items which were classified into five domains related to quality of life. These domains included acute and chronic symptoms, self-care, mobility, physical activities and usual activities. All the items were recoded to provide a logical direction. Further, a Cronbach' alpha statistics was utilized check the scale reliability (alpha=0.87), which suggested the scale to reliable for further computation(18). A principle component analysis was utilized to compute a quality of life (QoL) score, which was further segmented into two parts, namely "poor QoL/non-poor QoL". A detailed description of the items used in the generated of QoL scores is provided in the Supplementary Information 1. The third health outcome was a health score, which was based on the question: "Think about a scale of 0-100, with zero being least desirable state of health that you could imagine and 100 being the perfect health. What number, from 0 to 100 would you give to the state of your health. On average over the last three days? 
A descriptive analysis was used to study the background characteristics of the working age sample under consideration. Additionally, a weighted prevalence was computed for all the 18 chronic disease conditions included in the present study. To identify multimorbidity patterns among the working agegroup population a latent class analysis(LCA) approach was carried out $(14,19,20)$. All the eighteen chronic diseases, namelyacid peptic disease, arthritis, chronic back pain, diabetes, epilepsy, filariasis, hearing disorder, heart disease, hypertension, kidney disease, lung diseases, mental disorder, osteoarthritis, skin diseases, stroke, tuberculosis, thyroid diseases and vision disorderwere included as observed indicators. Four latent classes were included in the study. Fit indices Akaike Information Criterion (AIC) and Bayesian Information Criterion (BIC)(lowest values were indicative of the best fitting model) were used to identify the optimal number of latent classes to be included in the study $(14,19,20)$. After identification of the optimal number of latent disease classes, all the units (sampled individual/participants) were segregated into one of the identified latent class using the computed probability of membership $(14,19,20)$. Additionally, item-response probabilities were utilized to assign labels to the identified latent disease classes, i.e. the labels were based on theitem(s) (disease(s)) with higherprobabilities $(14,19,20)$.

In the present analysis only two latent disease classes were identified, out of which the first group had low item-response probabilities of all the eighteen-disease included, and was therefore labelled as 'low comorbidity' group. This 'low comorbidity' group was considered as the base outcome for the unadjusted (bivariate) and adjusted (multivariable) binary logistic regression. Multivariable binary logistic regression was adjusted for age, sex, ethnicity, education level, marital status, socio-economic status, residence, health insurance, and type of facility and was used to identify the correlates of being in the second latent disease class as compared to 'low co-morbidity' group. Linkages of the identified latent disease classes were observed with three perception-based health outcomes, namely poor self-rated health, poor quality of life and health score. To study the association between latent disease classes and perception-bases health outcomes chi-squared tests of significance was performed.

Data wrangling, analysis and visualization were performed using R studio Version 1.3.1093, (R Studio, Inc. PBC) and MS Excel. The r package 'poLCA' (2014) was used to conduct LCA(21). All the estimates computed in this study are derived by applying appropriate sampling weights derived utilizing the surveys sampling plan.

\section{Results}

The background characteristics of the study participants in presented in Table 1. The findings suggest that $51.72 \%$ of the study participants belonged to the age-group 15-34 years. Out of the total working age population $51.66 \%$ were male and $55.32 \%$ belonged to non-aboriginal ethnicity. About $36 \%$ of the study sample had an education level of secondary or above. Seventy five percent of the individuals were in a marital union, and $52.97 \%$ reported to be above poverty line. About $61 \%$ of the participants did not have any health insurance and $65.53 \%$ attended the secondary health facility for curing their ailment. 
The prevalence of chronic diseases is presented in Figure 1. Our analysis suggests that $2.4 \%$ of the individuals in the working age-group were affected with multimorbidity. The findings suggest that among the working age population, skin disease (5.99\%), hypertension (5.92\%), arthritis (4.91\%), acid peptic disorder $(3.87 \%)$, diabetes $(3.49 \%)$, and chronic back pain $(1.76 \%)$ were the six most commonly occurring disease conditions.

Table 2 illustrates the findings from the Latent model fits. For the present analysis four latent classes were taken into consideration. Smallest values of AIC and BIC were utilized to identify the optimal number of latent classes. Findings suggest that latent class 2 has the lowest AIC (7605.7) and BIC (7826.8) values and therefore, two latent classes were acknowledged from the study sample. As shown in Table 3, these classes were assigned labels on the basis of the item-response probabilities, which were low co morbidity' and 'Hypertension-Diabetes-Arthritis', respectively. Each of the study participant was segregated into one of the two identified latent classes based on the highest item-response probability. Around sixty seven percent of the participants belonged to 'low co morbidity' class, whereas $32.89 \%$ belonged to 'Hypertension-Diabetes-Arthritis' group. The 'low co morbidity' group included those with low prevalence of all the assessed chronic diseases, whereas, 'Hypertension-Diabetes-Arthritis 'included individuals with high probabilities of hypertension, diabetes, and arthritis, with latent class proportion of $22.10 \%, 10.6 \%$ and $10.2 \%$, respectively.

Table 4 provides the description of two latent classes identified in the present study. In the 'low co morbidity' group, $51.90 \%$ of the participants belonged in the age-group $15-34$ years. Around $52 \%$ of the individuals in 'low co morbidity' group were males, 55\% belonged to non-aboriginal ethnicity group, 36\% had education level secondary and above, $74.68 \%$ were in a marital union, $52.82 \%$ reported to be above poverty line, $71.79 \%$ resided in urban areas, $61.13 \%$ had no health insurance, and $20.17 \%$ attended tertiary healthcare facility for curing their ailment. The 'Hypertension-Diabetes-Arthritis' group constituted 53\% males, $67 \%$ of the non-aboriginal population, $39 \%$ not educated, $95 \%$ in marital union, $53 \%$ above the poverty line, $67 \%$ from urban areas, and $60 \%$ with no health insurance.

Binary logistic regression was adjusted for age, sex, ethnicity, education level, marital status, socioeconomic status, residence, health insurance, and type of facility. The findings highlighted that age, ethnicity, and place of residence were found to be significantly associated with the being in one of the multimorbid groups. The findings suggest that with increasing age [(35-49 years: AOR=9.69 $(5.69,16.64)$; 50-64 years:10.80 $(3.89,15.77)]$ and belonging to a non-aboriginal ethnicity [AOR=1.37 $(1.02,1.83)]$ increased the risk of being in the "Hypertension-Diabetes-Arthritis' group compared to 'low-co morbidity' group. Whereas, residing in urban areas $[\mathrm{AOR}=0.72(0.53,0.98)]$ reduced the risk of being in the "Hypertension-Diabetes-Arthritis' group by compared to 'low co morbidity' group.

The mean health score reported by the individuals in the 'Hypertension-Diabetes-Arthritis' group was 39.9 (scale $0-100$ ) compared to 46.9 by their counterparts as depicted in Figure 2.

\section{Linkages of latent disease classes with selected health outcomes}


The findings from the analysis suggests a statistically significant association between latent disease classes with self-rated health $(p=0.000)$, quality of life $(p=0.000)$ and health score $(p=0.000)$. The study highlighted that $49.96 \%$ of the individual in the 'Hypertension-Diabetes-Arthritis' group reported poor quality of life, whereas $30.19 \%$ reported poor self-rated health (SRH) compared to only $10.73 \%$ reporting poor SRH in the "low co morbidity group".

\section{Discussion}

The study indicates the prevalence and patterns of multimorbidity among young working age group populations in primary care setting. The prevalence of multimorbidity was $2.4 \%$ in working age group and the most common conditions were skin diseases, hypertension, arthritis, acid peptic disorder, diabetes, and chronic back pain. Latent class analysis found two groups i.e. 'low co morbidity' and 'HypertensionDiabetes-Arthritis'. Hypertension-Diabetes-Arthritis' group was significantly associated with age, nonaboriginal ethnicity, residence in rural area, and poor self-rated health, quality of life and health score.

Similar to other studies from India increase in age is the most common risk factor for the higher morbidity group. (22-24) In contrast to most of studies from India where female gender is found to be predisposed for multimorbidity $(11,23,25)$, in our study gender is not a risk factor for higher morbidity group. Hence, the relationship of multimorbidity with gender among the young adults does not seem similar to that in elderly and needs further assessment. We have found that chances of being in 'Hypertension-Diabetes-Arthritis' group is higher among rural population. Other studies from India have also highlighted the growing burden of multimorbidity among rural India. $(25,26)$ Growing burden of multimorbidity even among rural young's is a concern for Indian health system. Although there are auxiliary nurse midwife (ANM) and accredited social health activists (ASHAs) who are the main link between the community and health system i.e Primary Health Care Centre (PHCs), there primary work is still oriented towards maternal and child care and they currently have very limited training in the field of non-communicable disease. In addition to this, there are paucity of qualified MBBS doctors (allopathic doctors) in rural India and PHCs are often managed by AYUSH (non-allopathic alternative system) physicians. $(27,28)$

As different studies include different diseases for multimorbidity definition, comparing the pattern of multimorbidity from our study is unfeasible. Furthermore, there is lack of data on multimorbidity in productive age group. A recent community based study from Kerala from productive age group found prevalence of multimorbidity to be $45 \%$, reasons for high prevalence is that study are higher lower age limit cut off ie. 30years, whereas our study includes participants aged 15 years and above. Also, that study includes participants with higher blood pressure and blood sugar reading measured at the time of study as hypertension and diabetes whereas our study included only doctor diagnosed hypertensive and diabetic participants.(29)

A multi-country study conducted on national databases from high and low middle income countries among participants aged 50 years and above have found hypertension, cataract, and arthritis as the most 
prevalent co-morbid conditions. Most common patterns found in this study were" cardio respiratory"(angina, asthma, and chronic obstructive pulmonary disease), "metabolic" (diabetes, obesity, and hypertension), and "mental articular"(arthritis and depression)(30) Studies from across the world and India also found these as common multimorbidity clusters.(25,31-34)UK bio-bank study on participants aged 40 years and above has also highlighted that diabetes, hypertension and asthma and usually the common clusters found(35) Another study from nationally representative data of Danish Adults aged 16 years and above had identified seven classes: 1) Relatively healthy; 2) hypertension; 3) Musculoskeletal Disorders; 4) Headache-Mental Disorders; 5) Asthma-Allergy; 6) Complex Cardio metabolic Disorders; and 7) Complex Respiratory Disorders. However, patterns can't be compared they have also identified poor health-related quality of life in patients with multimorbidity clusters in comparison to relative healthy.(14) Other studies also shows poor health related health among patient with multimorbidity. $(8,24,36)$

From previous studies and our study finding we can postulate that hypertension, diabetes, asthma and arthritis are few of the most common co morbid conditions in the multimorbid people and affects patients quality of life and the multidisciplinary approach targeting these diseases could be helpful for the management for patients with multimorbidity. The national programme for prevention and control of cancer, cardiovascular disease, diabetes and stroke (NPCDCS) in India have recently include Chronic Obstructive Pulmonary Disease (COPD), Chronic Kidney Disease (CKD), Non Alcoholic Fatty Liver (NAFLD) and TB program. $(37,38)$ Integration of all these program was important because of their common risk factors such as obesity, alcohol use, diabetes etc and will lead to holistic management of these disease in future. Despite arthritis being the part of most common disease combination both is young and old population it is still not part of our national programme. Also, there is dearth of rheumatology specialist in India which leads to late diagnosis and mismanagement of patient with arthritis. Therefore, there is need for integration of arthritis management in NPCDCS program and capacity building of primary care physician for its diagnosis and management. Multimorbidity thus requires a multifaceted approach which can be well integrated and approached with ease. [39, 40,41,42]

Strengths and limitations: Most of studies on multimorbidity in India are from the older population, anticipating the growing prevalence of multimorbidity among working age group studying the prevalence, patterns, and its health impact in working age population are pivotal. Also, to the best of our knowledge this is first study from India, to identify the pattern of diseases using latent class analysis among working class group as most of the studies usually report most common dyad and triads. Although the data of chronic conditions are self-reported we have cross verified the medical records to confirm the diagnosis. Another limitation is association observed doesn't infer causality because of cross-sectional study design.

\section{Conclusion}

Latent class analysis found two groups i.e. 'low comorbidity' and 'Hypertension-Diabetes-Arthritis'. Hypertension-Diabetes-Arthritis' group was significantly associated with age, non-aboriginal ethnicity, residence in rural area, and poor self-rated health, quality of life and health score. Study findings vary 
owing to the differential cut off values used. There needs to be uniformity in deciding and defining where to start. Moreover, there is a shift in causation of diseases as a result of which preventive measures also need to be taken much prior.

Institutional Ethical Clearance was taken and there are no conflicts of interest.

\section{Declarations}

Conflicting Interest: None declared

Financial support and sponsorship: The project has received support from the Department of Health \& Family Welfare, Govt. of Odisha.

Acknowledgement: We acknowledge the contribution of all those involved in the project.

\section{Contribution Details:}

\begin{tabular}{|c|c|c|c|c|c|}
\hline - & SP & PP & PG & MP & PM \\
\hline Concepts & $\sqrt{ }$ & $\sqrt{ }$ & & & \\
\hline Design & $\sqrt{ }$ & $\sqrt{ }$ & & & \\
\hline Definition of intellectual content & $\sqrt{ }$ & $\sqrt{ }$ & $\sqrt{ }$ & & $\sqrt{ }$ \\
\hline Literature search & $\sqrt{ }$ & $\sqrt{ }$ & & $\sqrt{ }$ & $\sqrt{ }$ \\
\hline \multicolumn{6}{|l|}{ Clinical studies } \\
\hline \multicolumn{6}{|l|}{ Experimental studies } \\
\hline Data acquisition & $\sqrt{ }$ & & & $\sqrt{ }$ & $\sqrt{ }$ \\
\hline Data analysis & $\sqrt{ }$ & $\sqrt{ }$ & & $\sqrt{ }$ & \\
\hline Statistical analysis & & $\sqrt{ }$ & $\sqrt{ }$ & $\sqrt{ }$ & \\
\hline Manuscript preparation & $\sqrt{ }$ & $\sqrt{ }$ & $\sqrt{ }$ & & \\
\hline Manuscript editing & & & $\sqrt{ }$ & & $\sqrt{ }$ \\
\hline Manuscript review & $\sqrt{ }$ & $\sqrt{ }$ & $\sqrt{ }$ & $\sqrt{ }$ & $\sqrt{ }$ \\
\hline Guarantor & $\sqrt{ }$ & & & & \\
\hline
\end{tabular}

\section{References}

1. Academy of Medical Sciences. Multimorbidity: a priority for global health research. 2018. https://acmedsci.ac.uk/policy/ policy-projects/multimorbidity (accessed 11November 2020). 
2. Rosbach M, Andersen JS. Patient-experienced burden of treatment in patients with multimorbidity A systematic review of qualitative data. van Wouwe JP, editor. PLoS One [Internet]. 2017 Jun 23 [cited 2019 Jul 11];12(6):e0179916. Available from: http://www.ncbi.nlm.nih.gov/pubmed/28644877

3. Gill A, Kuluski K, Jaakkimainen L, Naganathan G, Upshur R, Wodchis WP. \&quot;Where do we go from here?\&quot; Health system frustrations expressed by patients with multimorbidity, their caregivers and family physicians. Healthc Policy [Internet]. 2014 May [cited 2019 Jul 11];9(4):73-89. Available from: http://www.ncbi.nlm.nih.gov/pubmed/24973485

4. O'Brien R, Wyke S, Watt GGCM, Guthrie B, Mercer SW. The 'Everyday Work' of Living with Multimorbidity in Socioeconomically Deprived Areas of Scotland. J Comorbidity [Internet]. 2014 Jan 28 [cited 2019 Jul 11];4(1):1-10. Available from: http://www.ncbi.nlm.nih.gov/pubmed/29090148

5. Garin N, Koyanagi A, Chatterji S, Tyrovolas S, Olaya B, Leonardi M, et al. Global Multimorbidity Patterns: A Cross-Sectional, Population-Based, Multi-Country Study. Journals Gerontol Ser A Biol Sci Med Sci. 2016 Feb;71(2):205-14.

6. Afshar S, Roderick PJ, Kowal P, Dimitrov BD, Hill AG. Multimorbidity and the inequalities of global ageing: a cross-sectional study of 28 countries using the World Health Surveys. BMC Public Health. 2015 Dec 13;15(1):776.

7. Pati S, Swain S, Hussain MA, van den Akker M, Metsemakers J, Knottnerus JA, et al. Prevalence and outcomes of multimorbidity in South Asia: a systematic review. BMJ Open. 2015 Oct 7;5(10):e007235.

8. Singh K, Patel SA, Biswas S, Shivashankar R, Kondal D, Ajay VS, et al. Multimorbidity in South Asian adults: prevalence, risk factors and mortality. J Public Health (Bangkok). 2019 Mar 1;41(1):80-9.

9. Arokiasamy P, Uttamacharya U, Jain K. Multiple Chronic Diseases and Their Linkages with Functional health and Subjective Wellbeing among adults in the low-middle income countries: An Analysis of SAGE Wave1 Data, 2007/10. 2013;

10. Banjare P, Pradhan J. Socio-Economic Inequalities in the Prevalence of Multi-Morbidity among the Rural Elderly in Bargarh District of Odisha (India). Chaturvedi S, editor. PLoS One. 2014 Jun 5;9(6):e97832.

11. Pati S, Swain S, Metsemakers J, Knottnerus JA, van den Akker M. Pattern and severity of multimorbidity among patients attending primary care settings in Odisha, India. Lee A, editor. PLoS One. 2017 Sep 14;12(9):e0183966.

12. Barnett K, Mercer SW, Norbury M, Watt G, Wyke S, Guthrie B. Epidemiology of multimorbidity and implications for health care, research, and medical education: a cross-sectional study. Lancet [Internet]. 2012 Jul [cited 2018 Jan 20];380(9836):37-43. Available from:

http://linkinghub.elsevier.com/retrieve/pii/S0140673612602402

13. Ward BW, Schiller JS. Prevalence of multiple chronic conditions among US adults: Estimates from the national health interview survey, 2010. Prev Chronic Dis [Internet]. 2013 [cited $2021 \mathrm{Feb}$ 26];10(4):1-15. Available from: https://pubmed.ncbi.nlm.nih.gov/23618545/ 
14. Larsen FB, Pedersen MH, Friis K, Gluèmer C, Lasgaard M. A Latent class analysis of multimorbidity and the relationship to socio-demographic factors and health-related quality of life. A national population-based study of 162,283 Danish Adults. PLoS One. 2017;12(1):1-17.

15. Olson JE, Takahashi PY, St. Sauver JM. Understanding the Patterns of Multimorbidity [Internet]. Vol. 93, Mayo Clinic Proceedings. Elsevier Ltd; 2018 [cited 2021 Feb 26]. p. 824- 5. Available from: https://pubmed.ncbi.nlm.nih.gov/29976373/

16. Prados-Torres A, Calderón-Larrañaga A, Hancco-Saavedra J, Poblador-Plou B, Van Den Akker M. Multimorbidity patterns: A systematic review [Internet]. Vol. 67, Journal of Clinical Epidemiology. J Clin Epidemiol; 2014 [cited 2021 Feb 26]. p. 254-66. Available from: https://pubmed.ncbi.nlm.nih.gov/24472295/

17. Pati S, Mahapatra P, Dwivedi R, Athe R, Sahoo KC, Samal M, Chandra Das R, Hussain MA. Multimorbidity and its outcomes among patients attending psychiatric care settings: An observational study from Odisha, India. Frontiers in Public Health. 2020;8:1078.

18. Puri P, Kothavale A, Singh SK, Pati S. Burden and Determinants of Multimorbidity Among Women in Reproductive Age-Group: A Cross-Sectional Study Based in India. Wellcome Open Res. 2020;5(275):1-15.

19. Park B, Lee HA, Park H. Use of latent class analysis to identify multimorbidity patterns and associated factors in Korean adults aged 50 years and older. bioRxiv. 2019;1-13.

20. Yap KH, Warren N, Allotey P, Reidpath DD. Chronic disease profiles of subjective memory complaints: a latent class analysis of older people in a rural Malaysian community. Aging Ment Heal. 2020;24(5):709-16.

21. Linzer DA, Lewis JB. poLCA: An R Package for Polytomous Variable Latent Class Analysis. J Statstical Softw. 2014;42(10):1-18.

22. Thankappan KR, Sivasankaran S, Sarma PS, Mini G, Khader SA, Padmanabhan P, et al. Prevalence correlates awareness treatment and control of hypertension in kumarakom, kerala: baseline results of a community-based intervention program. Indian Heart J. 58(1):28-33.

23. Himanshu H, Talukdar B. Prevalence of Multimorbidity (Chronic NCDS ) and Associated Determinants Among Elderly in India. Demogr India. 2017;p74.

24. Pati S, Swain S, Knottnerus JA, Metsemakers JFM, Van Den Akker M. Health related quality of life in multimorbidity: A primary-care based study from Odisha, India. Health Qual Life Outcomes [Internet]. 2019 Jul 5 [cited 2020 Dec 1];17(1):116. Available from:

https://hqlo.biomedcentral.com/articles/10.1186/s12955-019-1180-3

25. Kshatri JS, Palo SK, Bhoi T, Barik SR, Pati S. Prevalence and Patterns of Multimorbidity Among Rural Elderly: Findings of the AHSETS Study. Front Public Heal [Internet]. 2020 Nov 5 [cited 2021 Feb 26];8:582663. Available from: https://www.frontiersin.org/articles/10.3389/fpubh.2020.582663/full

26. Vadrevu L, Kumar V, Kanjilal B. Rising challenge of multiple morbidities among the rural poor in Indiaa case of the Sundarbans in West Bengal. Int J Med Sci Public Heal Online. 2016; 
27. Bajpai V. The Challenges Confronting Public Hospitals in India, Their Origins, and Possible Solutions. Adv Public Heal. 2014;2014:1-27.

28. WHO | The health workforce in India. WHO [Internet]. 2016 [cited 2021 Mar 5]; Available from: http://www.who.int/hrh/resources/hwindia_health-obs16/en/

29. C R, Jeemon P. Prevalence and patterns of multi-morbidity in the productive age group of 30-69 years: A cross-sectional study in Pathanamthitta District, Kerala. Wellcome Open Res [Internet]. 2020 Oct 8 [cited 2020 Oct 20];5:233. Available from: https://wellcomeopenresearch.org/articles/5-233/v1

30. Garin N, Koyanagi A, Chatterji S, Tyrovolas S, Olaya B, Leonardi M, et al. Global Multimorbidity Patterns: A Cross-Sectional, Population-Based, Multi-Country Study. J Gerontol A Biol Sci Med Sci. 2016 Feb;71(2):205-14.

31. Mini GK, Thankappan KR. Pattern, correlates and implications of non-communicable disease multimorbidity among older adults in selected Indian states: a cross-sectional study. BMJ Open [Internet]. 2017 Mar 8 [cited 2020 May 10];7(3):e013529. Available from: http://bmjopen.bmj.com/lookup/doi/10.1136/bmjopen-2016-013529

32. Steinman MA, Lee SJ, John Boscardin W, Miao Y, Fung KZ, Moore KL, et al. Patterns of multimorbidity in elderly veterans. J Am Geriatr Soc [Internet]. 2012 Oct [cited 2020 Oct 20];60(10):1872-80. Available from: /pmc/articles/PMC4133992/?report=abstract

33. Kirchberger I, Meisinger C, Heier M, Zimmermann A-K, Thorand B, Autenrieth CS, et al. Patterns of Multimorbidity in the Aged Population. Results from the KORA-Age Study. Thiem U, editor. PLoS One [Internet]. 2012 Jan 23 [cited 2018 Jan 20];7(1):e30556. Available from: http://dx.plos.org/10.1371/journal.pone.0030556

34. Violan C, Foguet-Boreu Q, Flores-Mateo G, Salisbury C, Blom J, Freitag M, et al. Prevalence, Determinants and Patterns of Multimorbidity in Primary Care: A Systematic Review of Observational Studies. Scuteri A, editor. PLoS One [Internet]. 2014 Jul 21 [cited 2019 Jul 4];9(7):e102149. Available from: https://dx.plos.org/10.1371/journal.pone.0102149

35. Zemedikun DT, Gray LJ, Khunti K, Davies MJ, Dhalwani NN. Patterns of Multimorbidity in MiddleAged and Older Adults: An Analysis of the UK Biobank Data. Mayo Clin Proc. 2018 Jul 1;93(7):85766.

36. Sum G, Salisbury C, Koh GCH, Atun R, Oldenburg B, Mcpake B, et al. Implications of multimorbidity patterns on health care utilisation and quality of life in middleincome countries: Cross-sectional analysis. J Glob Health. 2019;9(2).

37. Directorate General Of Health Services, Ministry of Health and Family Welfare, Government of India, National Programme for Prevention and Control of Cancer, Diabetes, Cardiovascular Diseases and Stroke (NPCDCS) [Internet]. [cited 2020 Jul 11]. Available from: https://dghs.gov.in/content/1363_3_NationalProgrammePreventionControl.aspx

38. Director General of Health Services MOHFW GOI. Operational Guidelines of Integration of Non Alcoholic Fatty Liver Disease with National Programme for the Prevention and Conrol of Cancer, 
Diabities Cardivascular, Disesase and Stroke (NPCDCS) [Internet]. [cited 2021 Mar 3]. Available from: https://main.mohfw.gov.in/newshighlights-41

39. Pati S, Pati S, Van Den Akker M, Schellevis FF, Jena S, Burgers JS. Impact of comorbidity on healthrelated quality of life among type 2 diabetic patients in primary care. Primary health care research \& development. 2020;21.

40. Panda M, Pathak R, Islam F, Agarwalla R, Singh V, Singh F. Interplay of multimorbidity and polypharmacy on a community dwelling frail elderly cohort in the peri-urban slums of Delhi, India. Journal of Family Medicine and Primary Care. 2020 Mar;9(3):1647.

41. Pati S, Mahapatra P, Kanungo S, Uddin A, Sahoo KC. Managing Multimorbidity (Multiple Chronic Diseases) Amid COVID-19 Pandemic: A Community Based Study From Odisha, India. Frontiers in public health. 2021 Feb 1;8:1026.

42. Kshatri JS, Palo SK, Bhoi T, Barik SR, Pati S. Associations of multimorbidity on frailty and dependence among an elderly rural population: Findings from the AHSETS study. Mechanisms of Ageing and Development. 2020 Dec 1;192:111384.

\section{Tables}


Table 1

Descriptive characteristics for working population (15-64 years)

\begin{tabular}{|lll|}
\hline Variables & Frequency $(\mathrm{N}=2912)$ & Percentage \\
\hline Age group (in years) & & \\
\hline $15-34$ & 1371 & 51.72 \\
\hline $35-49$ & 940 & 31.61 \\
\hline $50-64$ & 601 & 16.67 \\
\hline Sex & & \\
\hline Male & 1517 & 51.66 \\
\hline Female & 1395 & 48.34 \\
\hline Ethnicity & & \\
\hline Aboriginal & 1276 & 44.68 \\
\hline Non-aboriginal & 1636 & 55.32 \\
\hline Schooling & & \\
\hline No & 1031 & 34.49 \\
\hline Primary & 862 & 29.41 \\
\hline Secondary and above & 1019 & 31.25 \\
\hline Current Marital Status & & 36.03 \\
\hline In Union & 2238 & \\
\hline Not in Union & 674 & \\
\hline Socio-economic Status & & \\
\hline Below Poverty Line & 1374 & \\
\hline Above Poverty Line & 1538 & \\
\hline Place of Living & & \\
\hline Rural & & \\
\hline Urban & & \\
\hline Health Insurance & & \\
\hline No & & \\
\hline Yes & & \\
\hline Facility & & \\
\hline
\end{tabular}




\begin{tabular}{|lll|}
\hline Variables & Frequency $(\mathbf{N}=2912)$ & Percentage \\
\hline Primary & 430 & 15.28 \\
\hline Secondary & 1902 & 65.53 \\
\hline Tertiary & 580 & 19.19 \\
\hline
\end{tabular}

Table 2

Fit Statistics for Latent Class Analyses

\begin{tabular}{|lllllllll|}
\hline $\begin{array}{l}\text { Number } \\
\text { of } \\
\text { Latent } \\
\text { classes }\end{array}$ & $\begin{array}{l}\text { Number of } \\
\text { observations }\end{array}$ & $\begin{array}{l}\text { Number of } \\
\text { parameters } \\
\text { estimates }\end{array}$ & AIC & BIC & G^2 & $\mathbf{X}^{\wedge} 2$ & DF & LL \\
\hline 2 & 2912 & 37 & 7605.7 & 7826.8 & 120.8 & 333.5 & 2875 & -3765.9 \\
\hline 3 & 2912 & 56 & 7632.3 & 7966.9 & 109.4 & 265.4 & 2856 & -3760.2 \\
\hline 4 & 2912 & 75 & 7645.3 & 8093.59 & 84.5 & 226.1 & 2837 & -3747.7 \\
\hline 5 & 2912 & 94 & 7670.5 & 8232.32 & 71.7 & 369.4 & 2818 & -3741.3 \\
\hline
\end{tabular}


Table 3

Class Proportions and class-specific Probabilities from all Latent Class Model of Chronic Conditions.

\begin{tabular}{|lll|}
\hline Class & $\mathbf{1}$ & $\mathbf{2}$ \\
\hline Assigned label & Low comorbidity & Hypertension-Diabetes-Arthritis \\
\hline Class Proportion & 67.11 & 32.89 \\
\hline Item-response probabilities & & \\
\hline Arthritis & 0.039 & 0.102 \\
\hline Diabetes & 0.005 & 0.106 \\
\hline Hypertension & 0.001 & 0.221 \\
\hline Lung Disease & 0.007 & 0.001 \\
\hline Acid Peptic disease & 0.026 & 0.068 \\
\hline Back Pain & 0.015 & 0.030 \\
\hline Heart Disease & 0.004 & 0.003 \\
\hline Stroke & 0.002 & 0.001 \\
\hline Vision & 0.001 & 0.002 \\
\hline Deafness & 0.001 & 0.001 \\
\hline Kidney Disease & 0.003 & 0.001 \\
\hline Epilepsy & 0.003 & 0.001 \\
\hline Thyroid Disease & 0.008 & 0.001 \\
\hline Tuberculosis & 0.008 & 0.001 \\
\hline Filariasis & 0.002 & 0.001 \\
\hline Mental Disorder & 0.001 & 0.001 \\
\hline Skin Disease & 0.079 & \\
\hline Osteoarthritis & 0.002 & \\
\hline
\end{tabular}

Due to technical limitations, table 4 is only available as a download in the Supplemental Files section.

Figures 


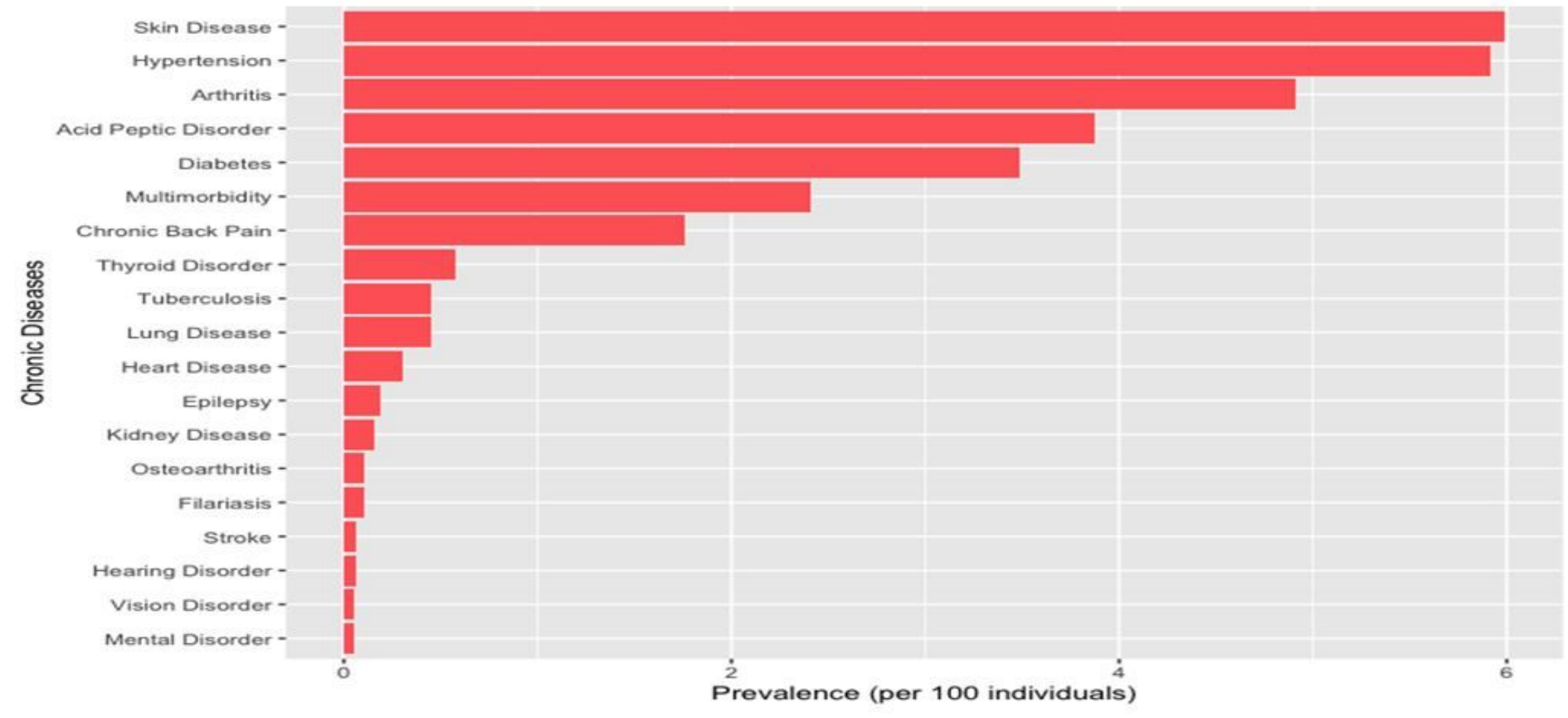

Figure 1

Distribution of chronic diseases among the working age-group

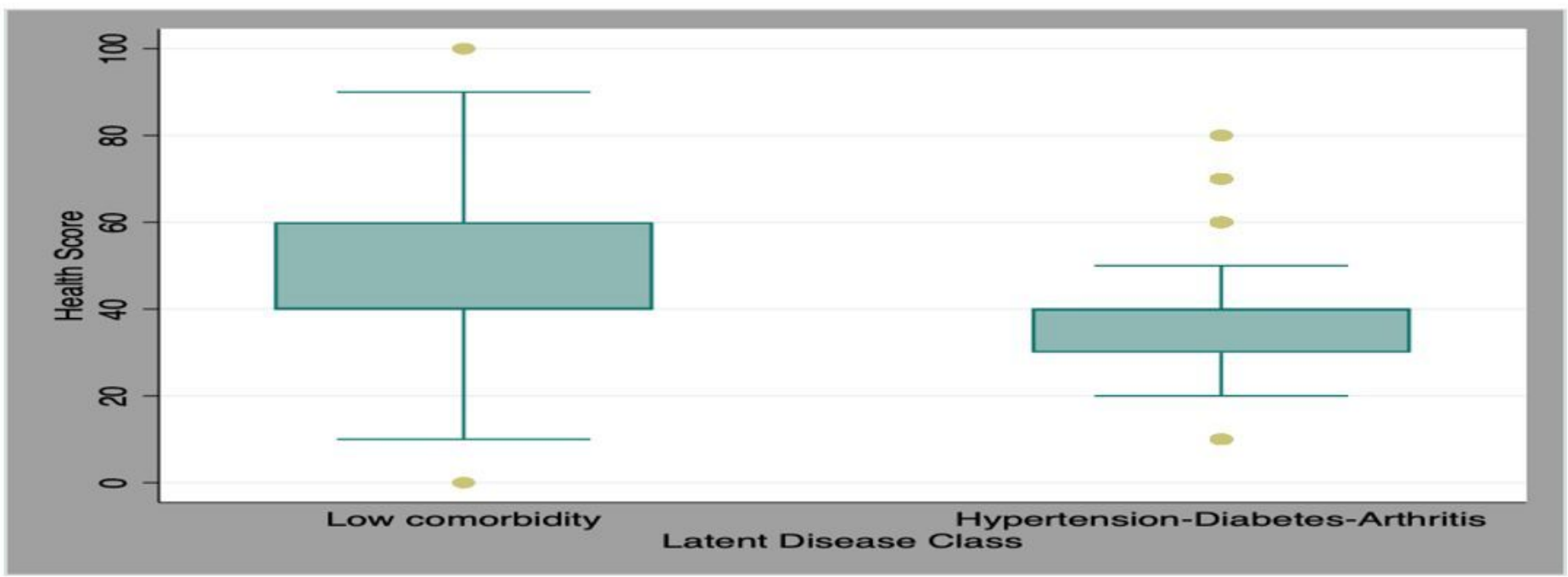

Figure 2

Boxplot depicting the distribution of health score between two latent disease classes (chi-squared pvalue $<0.000$ ) among older adults

\section{Supplementary Files}

This is a list of supplementary files associated with this preprint. Click to download. 
- Table4.jpg

Page 18/18 